\title{
Visual Cues on Products to Induce Healthy Food Choices Among Children from 8 to 12: An Abstract
}

\section{Claude Pecheux and Coralie Damay}

\begin{abstract}
This paper presents three experiments focusing on the impact of visual cues (red or green smileys) displayed on food products (1) on children's perceptions regarding healthiness and taste, as well as (2) on their preference for the product and their intent to request it. This set of experiments aims at providing insights into effective visual cues to encourage healthy choices and discourage unhealthy ones. The results from these three experiments provide interesting results to the debate of the need for a simplified information system about nutritional issues on product packages.
\end{abstract}

\footnotetext{
C. Pecheux $(\square)$

Université Catholique de Louvain, LSM, Louvain-la-Neuve, Belgium

e-mail: claude.pecheux@uclouvain.be

C. Damay

ISC Paris Business School, Paris, France

e-mail: coralie@damay.eu 